\title{
Aplicação de Jogos Educacionais com Realidade Aumentada
}

\author{
Ezequiel Roberto Zorzal, PPGEE/UFU, CEFET-SP, ezorzal@gmail.com \\ Mônica Rocha Ferreira de Oliveira, PPGEE/UFU, monica-rocha@ hotmail.com \\ Luciano Ferreira Silva, PPGEE/UFU, DCC/UFRR, luciano@mat.ufu.br \\ Alexandre Cardoso, PPGEE/UFU, alexandre@ufu.br \\ Claudio Kirner, PPGCC/UNIMEP, ckirner@unimep.br \\ Edgard A. Lamounier Jr. PPGEE/UFU, lamounier@ufu.br
}

Resumo: O jogo é uma ótima ferramenta de aprendizagem, na medida em que propõe estímulo e interesse ao aluno. Porém, recursos de jogos são limitados devido à complexidade imposta por determinadas tarefas. Este artigo propõe uma série de jogos educacionais desenvolvidos em ambiente de Realidade Aumentada, possibilitando um maior realismo e interatividade, visando à melhoria do processo de aprendizagem do educando. É relatada uma experiência de aplicação de um destes jogos em sala de aula e seus resultados apontam para um cenário de aprendizado muito promissor.

Palavras-chave: Realidade Aumentada, Jogos Educacionais, Interação.

\section{Implementation of Educational Games with Augmented Reality}

Abstract: Game is a great tool for learning, as it proposes stimulating interest in the student. However, the resources related to games are limited depending on the complexity imposed by certain tasks. This article presents a set of educational games developed with Augmented Reality technologies, allowing more realism and interactivity in the learning process of educating. It reported an experience of the application of one of these games in a classroom showing their results pointing to a scenario of very promising learning.

Keywords: Augmented Reality, Educational Games, Interaction.

\section{Introdução}

Os jogos sempre fascinaram as pessoas ao longo dos anos, sendo usados para o lazer e o desenvolvimento cognitivo. No entanto, apesar da criatividade de seus inventores, os jogos foram limitados por restrições de material e por leis físicas, relativas à fatores como a gravidade, o atrito, a inércia, o choque de corpos, etc. Essas restrições forçaram o desenvolvimento da maioria dos jogos sobre a mesa, dando-lhes características planares.

Com o uso do computador, a multimídia e a Realidade Virtual foram eliminadas algumas destas restrições, dando maior flexibilidade aos jogos. Porém surgiram novos obstáculos, como, por exemplo, a necessidade de treinamento em um ambiente estranho ao usuário e o uso de dispositivos especiais como joystick, luva e capacete. Assim, apesar dos benefícios de uma interação mais natural, as necessidades de equipamentos especiais e de treinamento para seu uso acabam limitando o alcance da Realidade Virtual.

Recentemente, a evolução científica e tecnológica propiciou a viabilização da Realidade Aumentada, que consiste na sobreposição de objetos virtuais gerados por computador em um ambiente real, utilizando para isso algum dispositivo tecnológico (Milgram, 1994). Por meio desta tecnologia é possível trazer os jogos virtuais do computador para o espaço do usuário, permitindo sua manipulação direta com as mãos ou por meio de elementos simples como placas ou cubos de papel ou madeira, 
familiares à maioria das pessoas. Nesse caso, os jogos passam a ser potencializados, através de maior capacidade de visualização e interação com os elementos virtuais do jogo, dispostos no espaço tridimensional, emitindo sons e mostrando animações, além de poderem ser replicados com baixo custo por serem quase estritamente software.

Isso propicia ambientes diversos, incluindo a exploração dos benefícios dos jogos educacionais, em função de suas características lúdicas, de envolvimento, de desenvolvimento de habilidades e de construção do conhecimento. Entretanto, para desenvolver tais ambientes é necessária a utilização de algum software e dispositivos tecnológicos.

Para o desenvolvimento das aplicações deste artigo utilizou-se a ARToolKit (Augmented Reality Toolkit) (Kato et al., 2000), uma biblioteca, com código aberto e gratuita, apropriada para desenvolver aplicações de Realidade Aumentada, que faz uso de técnicas de Visão Computacional para o reconhecimento de padrões e inserção dos objetos virtuais no ambiente real.

A estratégia de concepção de soluções com uso da ARToolKit fundamenta-se em um conjunto de procedimentos. Inicialmente, a imagem capturada pela câmera é transformada em valores binários (Preto \& Branco). Essa imagem é analisada pelo software, procurando por regiões quadradas que possam indicar a existência de uma marca. Assim, quando uma marca (marcador) é reconhecida, ele examina o interior da mesma fazendo uma busca pelo símbolo desenhado. Em seguida, este símbolo é capturado e comparado com os símbolos pré-cadastrados na biblioteca. Por fim, se for encontrada alguma similaridade entre símbolos capturados com símbolos précadastrados, é considerado então que foi encontrado um dos padrões de referência. Dessa forma, a ARToolKit utiliza o tamanho conhecido do quadrado e a orientação do padrão encontrado para calcular a posição real da câmera em relação a posição real do marcador. Assim, uma matriz $3 \times 4$ é gerada, contendo as coordenadas reais da câmera em relação ao marcador. Esta matriz é usada para calcular a posição das coordenadas da câmera virtual. Se as coordenadas virtuais e reais da câmera forem iguais, o objeto virtual é desenhado precisamente sobre o marcador real.

Este trabalho mostra as características, recursos e algumas implementações de jogos educativos com Realidade Aumentada, além de apresentar os resultados obtidos com um estudo de caso, envolvendo a aplicação desta estratégia e um grupo de crianças do $2^{\circ}$ ano de uma escola do ensino fundamental.

A seção 2 introduz jogos como ambientes de aprendizagem e apresenta uma coleção de jogos desenvolvidos em ambiente de Realidade Aumentada pelo Grupo de Realidade Virtual da Universidade Federal de Uberlândia. A seção 3 apresenta o experimento realizado. Finalmente, na seção 4, são apresentadas as conclusões do trabalho.

\section{Jogos com Realidade Aumentada}

A forma lúdica e descontraída de um jogo faz com que ele se torne um excelente instrumento de aprendizado, na medida em que incentiva seus usuários aos processos de pesquisa, construção de habilidades e de estratégias.

O jogo permite que seu usuário estabeleça oportunidades de encontrar soluções, criar estratégias e interagir com outros usuários, ocasionando então, o processo de atividades colaborativas e ampliando as estratégias coletivas de uma maneira estimulante e lúdica. Assim, o jogo é reconhecido como meio de fornecer ao usuário um 
ambiente agradável, motivador, planejado e enriquecido, proporcionando a aprendizagem de várias habilidades (Valentim, 2005).

Kamii e Devries (1991) consideram que, para ser útil no processo educacional e estimular a autonomia, um jogo deve: propor alguma coisa interessante e desafiadora para os alunos resolverem; permitir que os estudantes possam se auto-avaliar; e possibilitar que todos participem ativamente do começo ao fim.

Os jogos podem ser apresentados em diversas maneiras, tais como no papel, verbal, manual ou eletrônico. Os jogos no papel, verbal e manual, não necessariamente necessitam de dispositivos tecnológicos para sua execução, fazendo com que o usuário vivencie um processo de interação natural. No entanto, os jogos eletrônicos permitem que os usuários passem por situações diversas em um mundo virtual, ultrapassando os limites da lógica e da imaginação, utilizando as mãos diretamente ou através de dispositivos especiais para apoiar a interação. A principal deficiência dos jogos eletrônicos convencionais é a necessidade de adaptação aos dispositivos de interface não naturais.

Portanto, ao ser desenvolvido, o jogo deve fornecer um ambiente enriquecido, capaz de estimular e enriquecer a experimentação do usuário por meio da interação, propiciando o desenvolvimento do raciocínio e da habilidade cognitiva.

Com o avanço tecnológico, através de técnicas de Realidade Aumentada, tornouse possível associar ao mundo real objetos virtuais e proporcionar ao usuário uma experiência natural, agradável e motivadora.

A Realidade Aumentada (Kirner, Siscoutto, 2007) combina o ambiente real com objetos virtuais produzidos por computador, gerando um único ambiente sobreposto ao ambiente físico disposto na frente do usuário, visualizados diretamente no capacete ou indiretamente no monitor, por exemplo.

Esta tecnologia permite que o usuário tenha uma interação atrativa e motivadora com tais ambientes, e por conseqüência, o desenvolvimento de habilidades e a construção do conhecimento.

Sendo assim, esta seção apresenta alguns exemplos de jogos com Realidade Aumentada, os quais foram desenvolvidos pelo Grupo de Realidade Virtual da Universidade Federal de Uberlândia.

\subsection{Quebra-Cabeça 3D}

A invenção do quebra-cabeça ocorreu aproximadamente na década de 1760. Nesse período, os desenhistas de mapas começaram a colar seus projetos em madeira e cortá-los em pequenos pedaços. Perceberam então, que a montagem dessas peças poderia ser utilizada para fins didáticos (Williams, 2005).

Com o passar do tempo, os quebra-cabeças passaram a ser, além de ferramentas para o aprendizado, instrumentos de entretenimento e diversão para as crianças. Temas foram adicionados às peças, como animais, paisagens, personagem de histórias, etc. Por essas e outras melhorias, os quebra-cabeças também se tornaram objeto de interesse do meio adulto, impulsionando a produção do brinquedo.

Geralmente os quebra-cabeças são constituídos por uma série de peças com formatos diferentes, que devem ser unidas para originar uma imagem. Neste tipo de brinquedo o jogador se depara com um problema, fazendo com que passe por processos 
de raciocínio lógico e espacial planar em busca de uma solução válida, envolvendo planejamento, identificação e posicionamento das peças na mesa.

No quebra-cabeça 3D, o objetivo é montar um modelo qualquer com algumas peças que se encaixam. Estas peças são associadas a marcadores montados em cubos de madeira com seis faces. A princípio foram criadas apenas cinco peças, que encaixadas corretamente montam o quebra-cabeça, o que pode fazer parecer demasiadamente fácil a montagem do modelo. Porém, em cada um dos cinco cubos foi cadastrada a mesma peça nas seis faces, variando sua posição, orientação e escala (Figura 1), tornando assim a solução do enigma bem mais complexa e desafiadora, possibilitando inclusive mais de uma solução possível, pois se as mudanças nas peças forem similares em todos os cubos, seis soluções diferentes são possíveis, variando ao final a posição, orientação ou escala do modelo montado.

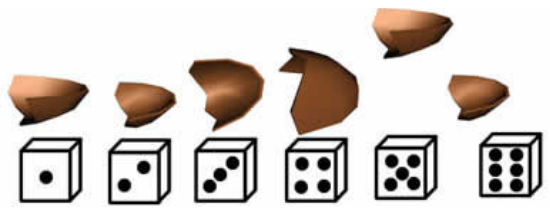

Figura 1. Objeto virtual com ângulos, escalas e posições diferenciadas.

Esta variação do quebra-cabeça pode ser utilizada tanto para entretenimento quanto para outros fins, como desenvolvimento de raciocínio espacial e treinamento.

A Figura 2 mostra o ambiente desta modalidade de quebra-cabeça.

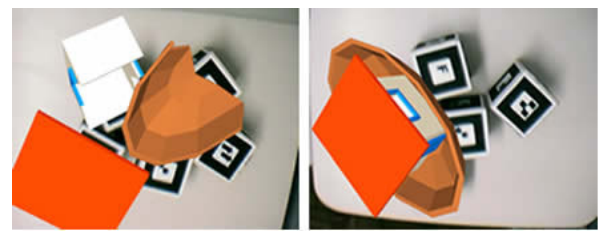

Figura 2. Ambiente do quebra-cabeça 3D.

\subsection{Quebra-Cabeça Ordenador}

O quebra-cabeça do tipo ordenador utiliza um princípio de um jogo muito conhecido, onde existe um quadro com diversas células de quadrados, que precisam ser rearranjadas para formar uma sequiência de números, figura ou símbolo.

Nesse caso, foi construído um jogo semelhante, utilizando papel cartão e os símbolos anexados são marcadores que, ao serem reconhecidos pela ARToolKit, mostram, ao jogador, objetos virtuais sobrepostos a eles. Esses objetos virtuais podem ser trocados com o auxílio de uma placa de controle (Santin, 2004), que corresponde a um marcador auxiliar. Ao ser colocado no campo de visão da webcam, a placa de controle faz com que seja executado um processo de alteração na identificação do objeto virtual com seus respectivos marcadores, fazendo com que eles recebam um novo valor em sua identificação e conseqüentemente um novo objeto virtual associado. Isto pode, por exemplo, alterar a formação de números para letras ou até mesmo um objeto 3D com recortes, que, ao ser montado, apresenta comportamento semelhante ao quebra-cabeças 3D citado na subseção anterior. A Figura 3 apresenta o cenário do quebra-cabeça ordenador. 


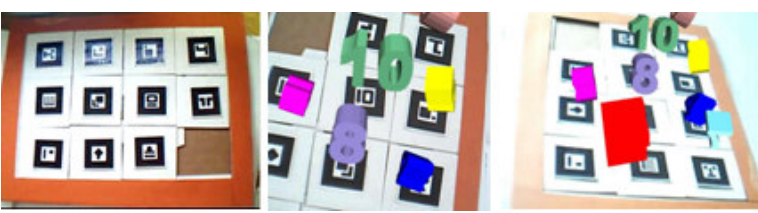

Figura 3. Cenário do quebra-cabeça ordenador.

\subsection{Torre de Hanói}

A Torre de Hanói é composta por uma base com três pinos dispostos na posição vertical e de um certo número de discos perfurados em seu centro, com diâmetros diferentes. Inicialmente, os discos são colocados em um pino de forma ordenada, ficando o de maior diâmetro embaixo e o de menor diâmetro em cima, constituindo uma torre.

O objetivo do jogo é transferir a torre, movendo um disco de cada vez, de um pino origem para um pino destino, usando um terceiro pino como auxiliar, com a restrição de que um disco menor nunca fique debaixo de um disco maior. O número mínimo de movimentos necessários para transferir a torre de um pino de origem para o destino é calculado pela fórmula $2^{n}-1$, onde $n$ é o número de discos (Ortega, 2002). Assim, em um jogo constituído de 3 discos, por exemplo, o usuário teria que fazer no mínimo 7 movimentos para realizar a transferência completa da torre. Este jogo exige raciocínio de planejamento, identificação de peças e posicionamento espacial restrito aos pinos.

Nesta aplicação, foram confeccionados quatro cubos, cada um com quatro marcadores de referência. Cada cubo representa um disco, sendo que cada face marcadora permite colocar o respectivo disco em uma posição no espaço.

$\mathrm{Na}$ lateral de cada cubo, foram impressos números de um a quatro, servindo como auxílio ao usuário para indicar as posições de cada face. A Figura 4 ilustra o posicionamento do disco vermelho no espaço, em função do posicionamento das faces do cubo. Os cubos dos outros discos não foram mostrados.

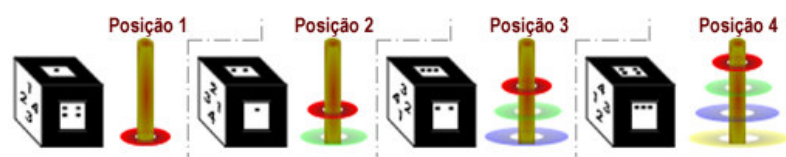

Figura 4. Posição do disco referente à sua marca.

Este novo método de jogo é interessante, pois além das características do jogo tradicional, ele apresenta outras que fazem com que o jogador exercite sua capacidade de raciocínio espacial e seqüencial. Como o disco não cai, cabe ao usuário descobrir sua posição espacial para que ele seja posicionado adequadamente sobre a torre parcial. Isto é obtido com a manipulação do cubo correspondente, escolhendo-se o disco na altura correta para cada caso. A Figura 5 mostra a Torre de Hanói desenvolvida com Realidade Aumentada.

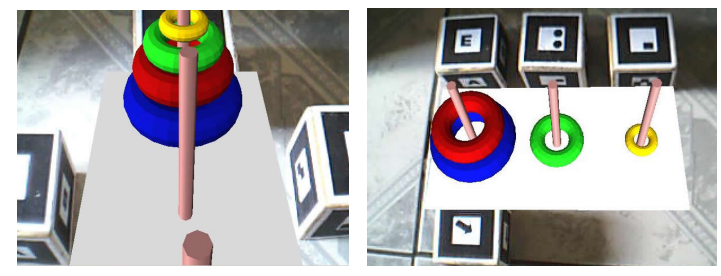


Figura 5. Torre de Hanói com Realidade Aumentada.

\subsection{Cubo Mágico}

O cubo mágico (Zhou et al., 2004) é um jogo constituído por um conjunto de oito cubos individuais de madeira ou plásticos interligados. Esse conjunto se desdobra resultando em diversas formas. Em cada face dos cubos individuais há uma imagem impressa. Ao desdobrar o conjunto, essas imagens se unem formando uma figura por completo. Este jogo não oferece muitos desafios, a não ser a habilidade de manuseio espacial e contemplação das imagens geradas.

Nesta aplicação, foi feita uma alteração na ARToolKit, de forma que além de disparar a visualização de um objeto ou cenário virtual sobre o marcador, é disparado também o acionamento de um trecho de gravação de áudio. Assim, em cada posição formada pelo cubo mágico, pode-se ver a cena virtual correspondente e ouvir sons, relatos ou trechos de uma história. Posicionando corretamente e em seqüência o cubo mágico no campo de visualização da webcam, o usuário poderá ver e ouvir uma história, por exemplo. Como aplicação, foi relacionada a esse jogo a história bíblica de Davi e Golias. A Figura 6 (a) apresenta os cenários virtuais que contam a história e seus respectivos marcadores de referência.

O cubo mágico com Realidade Aumentada permite que o usuário assista a história bíblica de Davi e Golias em um ambiente 3D, podendo inclusive examinar todos os ângulos, escutar a narração e a fala dos personagens e ouvir sons do ambiente virtual. Isso é conseguido através do posicionamento correto dos cubos.

Apesar do cubo mágico com Realidade Aumentada não alterar significativamente o correspondente físico, ele pode introduzir elementos novos como a narração. Além disso, é possível usar uma placa de controle que, usando a mesma face do cubo mágico, pode alterar a visualização da cena e da narração a cada entrada. Isto permite ampliar a capacidade do cubo mágico, fazendo que cada uma de suas faces seja uma história diferente. A Figura 6 (b) mostra o ambiente da aplicação do cubo mágico.

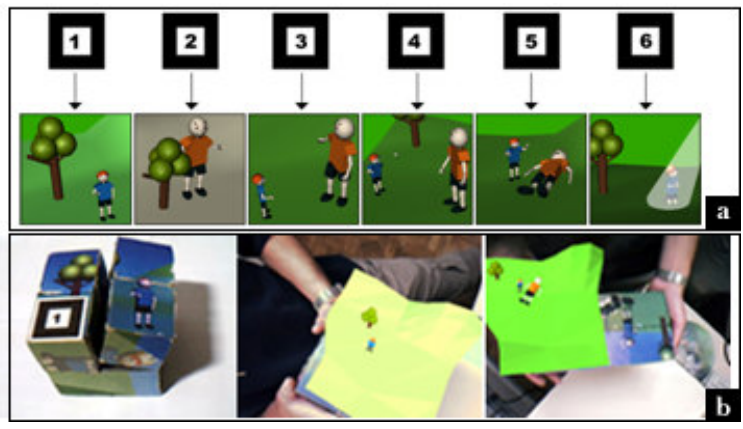

Figura 6. (a) Cenas virtuais e seus respectivos marcadores. (b) Cubo Mágico.

\subsection{Jogos de Palavras}

A proposta deste jogo é fazer a junção de letras para formar palavras e resgatando a imagem referente com técnicas de Realidade Aumentada para enriquecer os resultados finais.

A ARToolKit utiliza marcadores de referência com formas retangulares ou quadradas. Essas marcas não precisam ser necessariamente uma peça inteiriça, podendo ser compostas por vários fragmentos, desde que ao final o marcador formado esteja satisfatoriamente alinhado e possibilite o reconhecimento do padrão quadrado ou 
retangular. Baseando-se nisso, foram desenvolvidos marcadores com letras em seus interiores, e cadastradas combinações de palavras, formando assim marcadores compostos. Quando o usuário forma uma sequiência de letras previamente cadastrada, o ARToolKit mostra um objeto virtual associado àquela combinação.

A Figura 7 (a) apresenta alguns modelos de placas cadastradas junto aos seus respectivos objetos virtuais, usando palavras em inglês.

Essas características fazem desse jogo, além de um ótimo entretenimento, uma fonte de aplicações práticas como alfabetização, aprendizado de idiomas, entre outras.

O posicionamento no espaço dos objetos virtuais resultantes das montagens das palavras permite que sejam montados cenários virtuais ajustados pelo usuário, de forma que o jogo possa ser considerado um sistema de autoria baseado em palavras. Uma maneira de camuflar os marcadores, mostrando só os objetos, é colocar uma placa que gere uma base virtual um pouco acima da mesa, escondendo todas as palavras no monitor, mas mantendo-as visíveis na mesa para o usuário. A Figura 7 (b) mostra algumas peças utilizadas e o cenário do jogo.

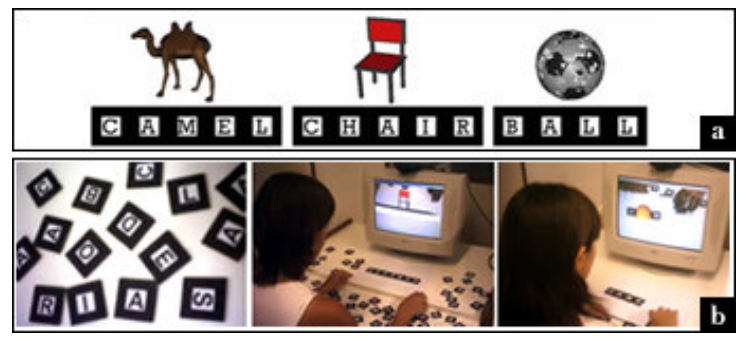

Figura 7. (a) Exemplo de placas e objetos virtuais correspondentes. (b) Peças e o ambiente do quebra-cabeça com palavras.

\section{Experimento Realizado}

O objetivo inicial do experimento foi verificar como as crianças reagiam a um ambiente educacional com Realidade Aumentada. Para realização deste, foram selecionadas 43 crianças do $2^{\circ}$ ano do ensino fundamental (antiga $1^{\mathrm{a}}$ série) de uma escola particular da cidade de Uberlândia (MG). Buscou-se investigar as relações destas crianças com tecnologias de Realidade Virtual e/ou Aumentada, como jogos computacionais e videogames, além do uso de artefatos tecnológicos nas aulas tradicionais, como computador, televisão e data-show.

O ambiente escolhido foi a biblioteca da escola, onde foram montados os computadores. O laboratório de informática não foi usado devido a ausência de câmeras e impossibilidade de instalação de programas por normas da escola.

Como as crianças eram muito novas ( 7 e 8 anos), optou-se por fazer uma apresentação inicial do Grupo de Realidade Virtual da Universidade Federal de Uberlândia e dos propósitos da pesquisa. Apresentou-se também o objetivo da participação das crianças na pesquisa, ressaltando a importância de respostas individuais e das sugestões. Foi escolhido o Jogo de Palavras (subseção 2.5), cuja proposta era fazer a junção de letras para formar palavras em inglês, resgatando a imagem referente com técnicas de Realidade Aumentada e apresentando conjuntamente uma frase sonora reforçando a pronúncia. As palavras escolhidas faziam parte das lições já aprendidas tradicionalmente na disciplina. Neste caso, utilizou-se uma placa de metal como apoio para as letras e estas foram construídas utilizando como fundo uma manta magnética. Isso facilitou a montagem e reconhecimento das palavras pelo software. V. 6 № 1, Julho, 2008 
Após estas apresentações, as crianças realizaram um pré-teste, uma pequena avaliação com as palavras da lição de inglês aprendidas na semana do experimento, na forma de associação palavra-figura. Vinte e uma crianças $(48.83 \%)$ obtiveram acertos acima de $80 \%$ nesta avaliação.

Então o grupo orientou as crianças sobre todos os procedimentos necessários para o funcionamento do software: escolher as letras e montar as palavras, tomando o cuidado para que as letras ficassem encostadas umas nas outras sobre as placas de metal. Em seguida, levantar a placa mostrando-a para o computador, até que na tela aparecesse uma imagem e fosse ouvido um som. A imagem poderia corresponder ao objeto escrito em inglês (e sua respectiva pronúncia seria ouvida) ou um $\mathrm{X}$ virtual, juntamente com o som da frase "Try again!". Neste caso, a criança deveria remontar a palavra e testar novamente.

Das crianças entrevistadas, apenas $4.65 \%$ não possuíam computador ou videogame em casa. Dentre as que possuíam, 34.88\% afirmaram ter limitações de horários para utilizar os equipamentos de computador e/ou videogame. Ainda, 6.97\% das crianças afirmaram não gostar de nenhum tipo de jogo de quebra-cabeça, adivinhação ou charadas. Uma das crianças relatou não ter nenhum tipo de jogo em casa.

Sobre o aplicativo, $93.02 \%$ das crianças disserem gostar dos gráficos apresentados na tela do computador e apenas $6.97 \%$ das crianças disseram que foi difícil trabalhar com os Jogo de Palavras. A Figura 8 apresenta um grupo de crianças (a) montando uma palavra, (b) apresentando a palavra ao computador e (c), visualizando o resultado na tela.

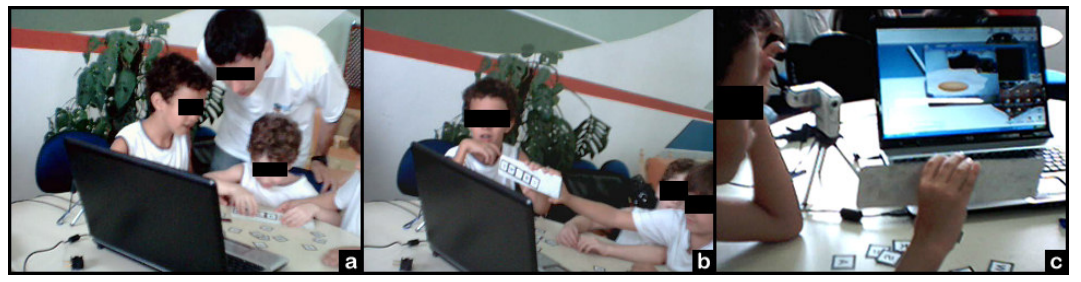

Figura 8. Fases do experimento.

Fazendo um comparativo com as aulas de Inglês, apenas $2.32 \%$ das crianças afirmaram preferir o método tradicional, sem uso de computador. Ainda, 2.32\% não souberam comparar os métodos. Porém, todas elas relataram "querer mais aulas desse tipo", incluindo as que não gostam de jogos e as que disseram ser difícil trabalhar com o mesmo.

As crianças, em geral, entenderam as explicações dos pesquisadores sobre Realidade Aumentada (88.37\%) e entenderam também os motivos de estar participando do experimento $(90.69 \%)$.

É interessante notar, dentre as justificativas apresentadas pelos participantes, que "divertido" e "legal" foram afirmações unânimes. Outros comentários destacaram-se: "Gostei porque aprendi Inglês", "gostei porque brincamos e aprendemos" e "porque foi uma nova forma de aprender". A Figura 9 mostra algumas expressões das crianças ao verem os resultados do quebra-cabeça na tela do computador, não deixando dúvidas sobre as justificativas por elas escritas. 


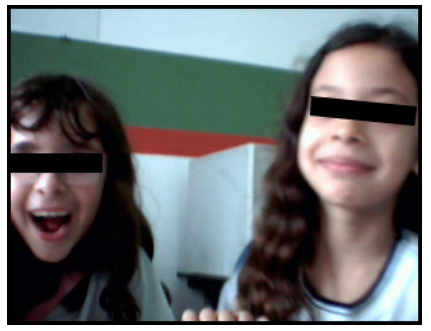

Figura 9. Expressões das crianças ao utilizarem o software.

Após todo o experimento, as crianças foram submetidas a um novo teste de inglês, já não mais associativo, mas com formato de cruzadinhas e caça palavras. $\mathrm{O}$ objetivo era verificar se houve aprendizado não só da relação palavra-imagem, mas da ortografia. O resultado foi surpreendente: $81.39 \%$ das crianças obtiveram nota acima de $80 \%$. Os resultados comparativos entre os testes podem ser vistos na Figura 10.

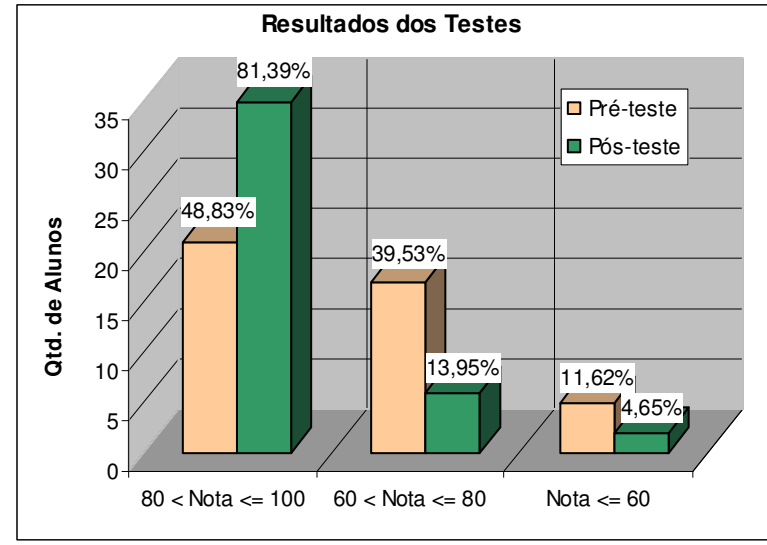

Figura 10. Gráfico dos resultados dos pré e pós-testes.

As normas de avaliação do software educacional infantil utilizada neste experimento seguiram a metodologia do MAQSEI (Metodologia de Avaliação de Qualidade de Software Educacional Infantil) (Atayde, 2003).

\section{Conclusões}

A Realidade Aumentada é uma tecnologia em expansão, com vasto campo de exploração, contribuindo de maneira significativa na área educacional. Ela garante um grande potencial na criação de jogos, permitindo uma interação natural de fácil adaptação e livre de dispositivos especiais. Os jogos com Realidade Aumentada permitem que os usuários tenham uma visão enriquecida e ampliada do ambiente. Ao lidar com os objetos virtuais tridimensionais sobrepostos ao cenário real, o jogador estimula sua capacidade de percepção e raciocínio espacial, conforme apresentado no jogo de palavras e quebra-cabeças 3D.

O cubo mágico com Realidade Aumentada, além de aumentar a visão do usuário com objetos virtuais postos em seu ambiente físico, também amplia sua audição com a execução de sons específicos para cada ação tomada mediante a esses objetos gerados. Esta característica pode ser incluída também no jogo de quebra-cabeça $3 \mathrm{D}$ e em outros jogos.

Os jogos com Realidade Aumentada têm um potencial muito grande de desenvolvimento, que até agora foi pouco explorado. A área de trabalhos colaborativos, 
especificamente, apresenta um espaço interessante de desenvolvimento, em função da existência de múltiplos usuários interagindo em um mesmo espaço compartilhado. Esses ambientes exigirão novas formas de interação, gerando novas interfaces que deverão facilitar o trabalho das pessoas e o seu desenvolvimento cognitivo. Esse campo, particularmente deverá ser objeto de exploração em trabalhos futuros.

O Grupo de Realidade Virtual da Universidade Federal de Uberlândia tem trabalhado no desenvolvimento de diversos jogos educacionais utilizando Realidade Aumentada, e atualmente trabalha em testes dos mesmos.

Na experiência relatada, observa-se uma população de crianças cada vez mais adaptadas aos dispositivos eletrônicos como computadores e/ou videogames e sedentas de material educacional tão atrativo quanto estes aplicativos. Acredita-se que o aspecto motivador da introdução de uma nova tecnologia no ambiente de aprendizado contribuiu para os resultados apresentados nesta pesquisa. Pretende-se, como trabalho futuro, um acompanhamento contínuo destas crianças, durante todo um ano letivo. A estratégia é dividi-las em dois grupos: um recebendo aulas com Realidade Aumentada e o outro, aulas tradicionais. Isso fornecerá um parâmetro entre o aprendizado com a tecnologia e sem a mesma, além de fornecer informações sobre motivação e envolvimento com as aulas.

\section{Agradecimentos}

Os Autores agradecem ao Conselho Nacional de Desenvolvimento Científico e Tecnológico (CNPq - Brasil) e à Coordenação de Aperfeiçoamento de Pessoal de Ensino Superior (CAPES) pelo apoio financeiro oferecido através do Programa de Doutorado no País.

\section{Referências Bibliográficas}

ATAYDE, A. P. R.; TEIXEIRA, A. B. M.; PÁDUA, C. I. P. S. MAQSEI - uma Metodologia de Avaliação de Qualidade de Software Educacional Infantil. XIV Simpósio Brasileiro de Informática na Educação - NCE - IM/UFRJ, Rio de Janeiro, RJ; 2003.

KAMII, C.; DEVRIES, R. Jogos em grupo na Educação Infantil: implicações da Teoria de Piaget. Tradução Marina Célia D. Latorre, Editora Artes Médicas, SP, 1991, p. 355 .

KATO, H.; BILLINGHURST, M.; POUPYREV, I. ARToolKit version 2.33 Manual, Novembro. 2000.

KIRNER, C.; SISCOUTTO, R. Realidade Virtual e Aumentada: Conceitos, Projetos e Aplicações. Livro do Pré-Simpósio; IX Symposium on Virtual and Augmented Reality, Petrópolis - RJ, 2007.

MILGRAM, P. et al. Augmented Reality: A Class of Displays on the RealityVirtuality Continuum. Telemanipulator and Telepresence Technologies, SPIE, V.2351, 1994.

ORTEGA, A. C.; FIOROT, M. A.; SILVA, L. C. M. O jogo Torre de Hanói em um contexto psicogenético. Acta Scientiarum, Maringá, PR, v. 24, n. 1, p. 151-158. 2002.

SANTIN, R. et al. Ações interativas em Ambientes de Realidade Aumentada com ARToolKit. Proc. of VII Symposium on Virtual Reality, SP, outubro. 2004.

VALENTIM, M. O. S. V. Brincadeiras infantis: importância para o V. 6 № 1 , Julho, 2008 
desenvolvimento

neuropsicológico.

Disponível

em:

$<$ http://www.navinet.com.br/ gualberto/Brincadeiras_Infantis.htm>. Acesso em: $20 \mathrm{de}$ Março de 2005.

WILliams, A. D. Jigsaw Puzzles - A Brief History. Disponível em: $<$ http://www.oldpuzzles.com/history.htm>. Acesso em: 10 de Dezembro de 2005.

ZHOU, Z. et al. Interactive Entertainment Systems Using Tangible Cubes, Australian Workshop on Interactive Entertainment, p. 19-22. 2004. 